\title{
SALAMANDRAS Y SILFOS: UNA APROXIMACIÓN A LOS ELEMENTALES EN LA LITERATURA FRANCESA DE LOS SIGLOS XVII Y XVIII
}

\author{
Teresa Baquedano Morales \\ Universidad de Zaragoza \\ teresab@unizar.es
}

\section{RESUMEN}

A partir del siglo XVII en Francia, algunas obras cercanas a los planteamientos teosóficos, introdujeron socialmente la temática de los seres elementales: espíritus o genios de pureza extrema que habitaban cada uno de los cuatro elementos y se comunicaban con el ser humano para conseguir la inmortalidad. Su presencia pasó de los tratados herméticos a los géneros literarios, en los que se establecía la tipología de estas criaturas y el modo de comportamiento con los humanos. De este modo, lo que apareció como una corriente hermética acabó adoptando un registro moralizante en la literatura, utilizando sus mismos recursos, para realizar una crítica contra un sistema filosófico cercano a la superstición en plena época de la Ilustración.

PALABRAS ClaVE: seres elementales, salamandras, silfos, corrientes herméticas, moral.

\section{RÉSUMÉ}

Depuis le XVIIe siècle, certains ouvrages reliés aux doctrines théosophiques introduisirent en France le sujet des êtres élémentaires: des esprits ou des génies d'une pureté extrême habitant dans chacun des quatre éléments et ayant des rapports avec les humains afin d'obtenir l'immortalité. Par la suite, leur présence découlant des traités hermétiques fut attestée dans les genres littéraires, où l'on dressât la typologie de ces 
créatures et leur comportement envers les êtres humains. Désormais ces premiers courants hermétiques adoptèrent finalement dans la littérature un ton moralisateur à l'aide des mêmes ressources, dans le but de critiquer un système philosophique proche de la superstition à l'époque des Lumières.

MOTS CLÉS: êtres élémentaires, salamandres, sylphes, courants hermétiques, morale.

Siguiendo el ejemplo de Paracelso en su Livre des Nymphes ${ }^{1}$, en la segunda mitad del siglo XVII se introdujo en Francia la traducción de la Lettre philosophique ${ }^{2}$, perteneciente lo más probablemente al Cosmopolita y traducida del alemán al francés el siglo anterior por Antoine Du Val. La carta refiere, en primer lugar, los diferentes elementos de la Creación, su orden y colocación, por los que se va entrehilando esa rueda del Universo que llega desde los pequeños seres de la naturaleza hasta el mismo Cielo de los astros celestes, donde se encuentra el fuego más puro y habita Dios en luz inaccesible.

Se reabre entonces una línea teosófica en la que se pondrán de manifiesto algunos de los planteamientos conocidos o predicados desde antaño, mediante los cuales la realidad sería doble, repartida entre un plano de lo sensible, lo empíricamente cognoscible, y del otro lado, lo imperceptible por los sentidos pero con plena existencia espiritual. Este segundo plano sólo es accesible a los que les es dada la capacidad de ver con clarividencia a estos seres que ayudan igualmente a construir el mundo y cuya apariencia física será exclusivamente producto de la superstición popular, pues su descripción no podrá ser nunca tomada como una imagen exacta de lo que son, sino como la expresión de una realidad simbólica más allá de la apariencia material ${ }^{3}$. Ésta, junto a otras obras de similares características, aparecían en un contexto con unos aires de cambio de corte racionalista, que pretendían arrojar luz y claridad en los paradigmas sociales de pensamiento, donde los seres elementales irrumpirían con fuerza empañando esa misma luz con una temática nada novedosa.

A fines de siglo XVII y coetánea de la Lettre philosophique, se publicaba en Francia Le comte de Gabalis ou Entretiens sur les sciences secrètes ${ }^{4}$ del abate Montfaucon de Villars, una obra que lograría desatar pasiones tanto a favor como en contra donde un cierto conde de Gabalis, mediante unas enseñanzas dirigidas a su discípulo neófito, declaraba abiertamente la existencia y su contacto con unos seres espirituales muy superiores cualitativamente al género humano. La obra tuvo tal éxito que conoció al menos doce ediciones posteriores en francés y algunas traducciones al inglés, avivando en algunos casos, y reavivando en otros, las inclinaciones por la magia y las ciencias ocultas

${ }^{1}$ Paracelso, Teophrastus B. Hohenheim (1998): Le livre des Nymphes, Pygmées, Sylphes et Salamandres et de tous les autres esprits, Paris, S. (éd.), Nîmes, C. Lacour.

2 Du VAL, Antoine (1659): Lettre philosophique, traduite d'Alleman en François, par Antoine Du Val, Paris, J. D'Houry.

3 STEINER, Rudolf (1923): Théosophie. Étude sur la connaissance suprasensible et la destinée humaine (trad.), Paris, P.U.F., p. 168

${ }_{4}$ VILlars, Nicolas de Montfaucon de [1670 (1788)]: Le comte de Gabalis ou Entretiens sur les sciences secrètes, Amsterdam-Paris, [s. n.], coll. «Voyages imaginaires, songes visions et romans cabalistiques» n. ${ }^{\circ} 34$. 
en plena época de la razón. Finalmente la obra fue condenada, así como su autor, a quien se le prohibió seguir predicando ${ }^{5}$ y moriría trágicamente tiempo más tarde víctima de un asesinato en el camino hacia Lyon.

El trasfondo de la historia presentada en Le comte de Gabalis se basa principalmente en la existencia de cuatro clases generales de espíritus o seres, residentes en cada uno de los cuatro elementos, y cómo éstos se relacionan con los humanos. Para una parte de la crítica el texto refleja una jerarquía de criaturas mitológicas recogidas de diversas tradiciones folklóricas, así como las enseñanzas de la Cábala medieval, la menos prestigiosa de las versiones conocidas. Esto último no es de extrañar dada la semejanza fonética con el nombre del protagonista, denominado algunas veces por error «Cabalis». En este caso los espíritus mencionados no serían «élémentaires», habitantes de un plano celeste muy superior, sino «élémentals» ${ }^{6}$, de carácter secundario, necesitados de la unión con el ser humano para obtener su inmortalidad, por lo que también reciben la denominación de íncubos y súcubos. Éstos se dividirían en cuatro órdenes diferentes, dependiendo del elemento al que pertenecen, es decir, silfos, salamandras, gnomos y ondinas ${ }^{7}$.

Sin embargo, otros creen que la exposición de los cuatro seres elementales procede directamente de la clasificación existente en la obra de Paracelso y de sus seguidores, que a su vez sí que profundizaba en las raíces folklóricas de la Antigüedad ${ }^{8}$. En este sentido, el siglo XVII basará todo su hacer en la herencia de las fábulas, la mitología y el folklore antiguos, así como la de otros pueblos de diferente tipología, desde la perspectiva de lo maravilloso9. Voltaire hablaría incluso del origen hindú de estos seres, como la primera cultura que inventara las salamandras, los gnomos, las ondinas y los silfos, aunque finalmente acabó por reconocer «si pourtant ce n'a pas été une idée naturelle à tous les hommes de peupler le ciel et les quatre éléments» ${ }^{10}$. El Dictionnaire de Littérature chrétienne remite directamente esta tetraclasificación a la escuela platónica, transformando los verdaderos espíritus elementales en seres de categoría más baja, renacidos de potencias superiores por la imaginación humana:

Les souvenirs mêmes de l'école de Platon redevinrent vivants dans cette transfiguration infernale et les esprits élémentaires dont ce philosophe composait sa grande âme du monde devinrent des lutins et des démons familiers ; le sylphes de l'air remplacèrent les classiques zéphyrs, les ondins, et leurs compagnes s'emparèrent de l'empire vacant des tritons et des nymphes; les gnomes pullulèrent dans les ateliers abandonnés des cyclopes, et les salamandres trouvèrent leur existence dans les flammes ${ }^{11}$.

\footnotetext{
5 SEEBER, Edward D. (1944): «Sylphs and other elemental beings in French literature since Le Comte de Gabalis (1670)», PMLA, 59:1, pp. 71-83.

${ }^{6}$ Guaita, Stanislas De (1890-1920): Essais de sciences maudites, vol. I, Paris, G. Carré, p. 90.

7 Bosc, Ernest, La doctrine ésotérique à travers les âges, vol. 2, Paris, Chamuel, 1899-1900, pp. 90-91.

8 SEEBER, Edward D., op. cit., p. 74.

9 DelaporTe, Victor (1891): Du merveilleux dans la littérature française sous le règne de Louis XIV [thèse pour le doctorat présentée à la Faculté des Lettres de Paris], Paris, Retaux-Bray, pp. 8-9.

${ }_{10}$ Voltaire, (1894): Fragments historiques sur quelques révolutions dans l'Inde in Euvres complètes, $\mathrm{t}$. XXIX, Paris, Hachette, p. 457.

11 «Croyance». Constant, Alphonse-Louis (1851): Dictionnaire de Littérature chrétienne, Paris, J.-P. Migne, p. 372.
} 
Los silfos tienen apariencia humana, amantes de la sabiduría y la ciencia, aunque las sílfides poseen un físico de tipo apolíneo, varonil, como las Amazonas ${ }^{12}$. En cuanto a los seres acuáticos, éstos están peor repartidos genéricamente y abunda más la especie femenina, que es de una belleza incomparable frente a la de cualquier mujer. Los pequeños gnomos guardianes de los tesoros de la tierra, ingeniosos y amigos del hombre hasta el punto de compartir sus riquezas, se presentan acompañados de las correspondientes gnomides, de pequeño tamaño aunque agradables y de curiosa vestimenta ${ }^{13}$. Por último, las salamandras, los más bellos y bellas de todos los cuatro seres porque pertenecen al elemento más puro, se dejan ver raramente por los humanos y son sirvientes de los filósofos, pero las menos deseosas de su compañía ${ }^{14}$. Los genios elementales que más páginas han ofrecido son los silfos y las salamandras, cuya belleza extrema y propiedades han atraído tanto como el elemento al que pertenecen. Del mismo modo, aunque con excepciones, la representación de personajes sílfidos tenderá a ser masculina, mientras que las salamandras seguirán usando mayoritariamente, como su mismo género indica, el femenino.

Sin embargo, la duda queda entre los que opinan sobre la veracidad de Le comte de Gabalis y califican la obra de rosacruz, o los que aseguran que se trata de una burla contra esta clase de doctrinas cabalísticas. Lo que es seguro, por otra parte, es la estela que esta obra ha dejado posteriormente, logrando sus mayores frutos entre los siglos XVIII y principios del XIX, donde los seres elementales se movían al compás marcado por Villars en su época.

La entrada en el siglo XVIII supone entonces una reformulación de estas teorías cabalísticas aplicadas a la literatura. Los nuevos paradigmas filosóficos y científicos ayudaron por un lado a desmitificar aquellos modelos obsoletos, pero no lograron erradicar completamente, al menos a nivel cultural, la utilización de estos motivos literarios que tantas herramientas ofrecerían a sus autores para prolongar la diversión, o desde un prisma mucho más serio transmitir un apólogo moral, como será en la mayoría de las ocasiones.

En los años que abarcan esa era, la literatura asistió a un verdadero apogeo de los temas mitológicos en el teatro y el ballet fundamentalmente ${ }^{15}$, abriendo una puerta por donde pudieron colarse los elementales. De ahí que el Marqués d'Argens, desde el tono de la seriedad, pudiera afirmar lo siguiente unos sesenta años más tarde tras la publicación de Le comte de Gabalis, en otras cartas donde también se establece un diálogo en la distancia entre el emisor y su receptor:

Je commence à croire, que bien des choses que je regardois comme ridicules, ne sont, ni impossibles, ni contraires à la bonne philosophie. [...] Quoi qu'il soit certain, que l'existence des gnomes, des silphes, des salamandres, et des ondins, ne soit pas véritable, elle n'a cependant rien de contraire aux lois ordinaires de la nature. [...] Quelle impossibilité y a-t-il qu'il y ait des corps animez, et composez d'une matiere subtile et déliée, qui ne tombent point sous nos sens $?^{16}$

12 VILlaRs, Nicolas, op. cit., p. 19.

13 Ibid., p. 20.

14 Ibid., p. 21.

15 Albouy, Pierre [(1968) 1969]: Mythes et mythologies dans la littérature française, Paris, Armand Colin, p. 45 .

${ }^{16}$ Lettre 121. Argens, Jean-Baptiste de Boyer (marqués de) (1738): Lettres juives ou Correspondance philosophique, historique et critique entre un juif voyageur et ses correspondans en divers endroits, La Haye, P. Paupie, pp. 1-2. 
No obstante, no todos los autores están dispuestos a aceptar la existencia sin más de estos elementales, que sin embargo se citan hábilmente junto a la preferencia de otras criaturas de tradición folklórica, aunque la intención última sea expresar con ironía la moda y el gusto de estas disciplinas tan herméticas como aparentemente engañosas:

Enfin s'il est des peuples enflammés,

Nourris de feu, sans être consumés ;

Que tels dictons soient vrais ou chimeriques,

Aucunement ne m'en suis soucié ;

Aux préjugés d'Auteurs cabalastiques. (vv. 6-10) ${ }^{17}$

Otros autores aprovecharán igualmente las primeras líneas de sus obras para proporcionar ciertas explicaciones sobre estos seres antes de iniciar la historia. Houdar de La Motte, en un tono menos serio quizá que el marqués d'Argens, proclama en verso a unos elementales un tanto menos perfeccionados:
Nous nous croyons dans l'Univers
La seule espèce qui raisonne
Point du tout. Le feu, l'onde et la terre, et les airs,
Logent encor mainte honnête personne ;
Tenant beaucoup de l'humain animal,
Raisonnant comme nous, tantôt bien, tantôt mal.
Les flots ont leurs Ondins, et la terre a ses Gnomes ;
Silphes habitent l'air, Salamandres le feu ;
Et ces Messieurs se font un jeu
De s'allier quelquefois chez les hommes. (vv. 1-10) ${ }^{18}$

A pesar de que existió una segunda parte de los Entretiens, la Suite du Comte de Gabalis ou Nouveaux Entretiens sur les sciences secrètes, publicada en 1708 y 1715, no obtuvo el mismo éxito que la anterior, puesto que, entre otras cosas, ya no existía esa marcada impronta del autor en la que se manifestaba ese doble sentido entre serio e irónico acerca de estas doctrinas ${ }^{19}$.

Uno de los primeros textos franceses dentro de la estela dejada por la obra de Villars, e influidos directamente por Le comte de Gabalis, fue la obra teatral La pierre philosophale de Thomas Corneille, hermano menor de Pierre, y publicada unos años más tarde que la obra de Villars. Sin embargo, la pieza no fue bien acogida y tan sólo contó con dos representaciones ${ }^{20}$. El texto se inserta dentro de la adaptación de los cuatro elementos al teatro, tan de moda en la época ${ }^{21}$.

17 «Le Lutin». GRÉCOURT, Jean-Baptiste Willart de (1761): Euvres diverses de Grécourt, t. II, Luxembourg (Paris), [s. n.], pp. 262-263.

${ }^{18}$ Houdar de la Motte, Antoine (1754): Les peuples élémentaires. Fable. In Lettres de La Motte, [s. 1. s. n.], pp. 204-205.

${ }_{19}$ BILA, Constantin (1925): La croyance à la magie au XVIIIe siècle en France dans les contes, romans et traités, Paris, J. Gamber, p. 97.

${ }^{20}$ Delaporte, Victor, op. cit., p. 123.

${ }^{21}$ DE LA GoRCE, Jerôme (2004): «La représentation des éléments dans le décor et le costume de théâtre en France», Les éléments et les métamorphoses de la nature: imaginaire et symbolique des arts dans la culture 
Entre sus personajes se encuentran los habitantes de los cuatro elementos y hasta hay lugar para el conde Gabalis, o más bien para su hijo. A imitación de Le comte de Gabalis, dos de los personajes principales, M. Maugis et Mme Raimond se obstinan en encontrar la piedra filosofal en los hornos de su laboratorio secreto para poder enriquecerse. Se trata de una comedia y en estos casos los personajes más crédulos, devotos de doctrinas herméticas, son engañados como víctimas de la mofa de los de su alrededor. De este modo se van asentando las bases de este motivo literario en el género tanto teatral como novelesco. La salamandra aparecerá en escena junto a las demás criaturas tras la exposición de los consabidos planteamientos cabalísticos, con una imponente apariencia y acompañada, como es la tónica general en las obras que utilizan estos seres como elementos teatrales, de una maquinaria ${ }^{22}$ que permitiría dar cuenta de las especiales características de estos genios.

Si hay un momento de alegría del que se hace partícipe al espectador es cuando de entre los personajes principales, M. Maugis y su hija, van a «recibir el honor» de preparar sus ojos filosóficamente para poder ver a los elementales y resolver sus respectivos matrimonios con alguno de ellos. En el momento en que su vista es consolidada para tal acontecimiento, ante ellos se alzan varias criaturas de las cuatro razas que al hilo de la ceremonia y llevados por la alegría propia de una comedia, bailan y cantan algunos versos en los que ellos son los personajes principales. Lo imposible se convierte en posibilidad en esta comedia, no para la relación de los elementales con el ser humano sino entre ellos mismos, acrecentando la atmósfera de extrañeza de la pieza y la de la mofa contra el avaricioso cabalista Maugis.

Les Quatre Elémens dancent en suite, et leur Dance estant finie, un Salamandre et un Ondin, chantent ces Paroles ensemble.

Le spectacle est assez beau

De nous voir unis ensemble.

On le trouvera nouveau ;

Mais il me semble

Que le feu peut souffrir l'eau,

Lors que l'Amour les assemble ${ }^{23}$.

A pesar del intento de Corneille y Donneau de Vizé de introducir este motivo literario, así como de continuar la saga de la novela cabalística de Villars en clave de comedia, el éxito se quedó a la puerta, al igual que el recuerdo de estas criaturas que tuvieron que esperar a algunos autores de cuentos de hadas así como a novelistas y dramaturgos, ya entrado el siglo XVIII. En un intento de racionalidad y moralidad, el abate de Bellegarde se quejaba así a principios de este siglo de lo fabuloso de las hadas, creadas a partir de estas doctrinas que arrastraron a los elementales hasta las páginas de la literatura:

européenne du XVI e au XVIII siècle, Actes du Colloque international de l'Opéra de Bordeaux (17-21 septembre 1997), Brunon, H., Mosser, M., Rabreau, D. (dirs.). Bordeaux, William Blake \& Co., pp. 255-261.

${ }^{22}$ Delaporte, Victor, op. cit., p. 123.

${ }^{23}$ CoRneille, Thomas, Donneau de Vizé, Jean (1681): La pierre philosophale. Comédie mêlée de spectacles, Paris, C. Blageart, pp. 25-26. 
Si l'on veut dire quelque chose de plus specieux en faveur des Fées, on peut attribuer leur origine à l'idée que de certains Philosophes ont euë, que tous les élemens étoient habitez par differens peuples ou differens génies ; que les Gnomes s'étoient emparez de la terre ; que les Ondins avoient choisi la mer pour leur partage ; que les Sylphes se promenoient dans l'air, et les Salamandres dans la region du feu ${ }^{24}$.

Los seres elementales continuaron en el ballet ${ }^{25}$ y el teatro produciendo sus frutos. En 1736 l'Académie royale de Musique representaba Les Génies ${ }^{26}$, algunas de cuyas entradas se marcaban por las piezas que correspondían a cada uno de los cuatro elementos. La tercera entrada correspondiente a la aparición de las salamandras, llevaba por título Les Salamandres, ou l'Amour violens, donde los nombres propios tanto del rey como de la princesa de los espíritus del fuego se insertan en la etimología ígnea y aparecen como otros personajes, algunos africanos ${ }^{27}$, probablemente por esta asociación del calor elevado a fuego, al igual que ya ocurriera en algunas obras medievales. Asimismo, veinte años más tarde se representaba la ópera Zoroastre con música de Rameau y texto de Cahusac, donde el papel protagonista estaba dedicado al sabio y mago persa rodeado de espíritus elementales, esparcidos por todas las esferas de la tierra para garantizar la armonía del universo, que en la obra liberaba a los pueblos sometidos bajo el poder del tirano Abramane ${ }^{28}$.

En lo concerniente a este mismo panorama literario de los elementales, hacia mediados de siglo se publica una curiosa obra que incluye a estos seres, subtitulada como Conte phisique. Ahí se aglutinan las cuatro órdenes de estas criaturas bajo una sola persona en un texto que se aproxima por lo misterioso de la forma y el contenido a una obra alquímica, a lo que se añade la perspectiva filosófica de la naturaleza tan extendida en las corrientes de pensamiento de esta época.

El protagonista, al hilo de la iniciación en los misterios de la naturaleza, es conducido por unos céfiros al sur de París hasta el edificio dedicado a la diosa Minerva. Allí, donde todo se torna transparente, se le muestran los objetos invisibles a los ojos humanos, impredecibles por su imaginación. En esos momentos el personaje divisa horrorizado en medio de tanta maravilla un terrible monstruo cuyo cuerpo estaba compuesto de una multitud de brazos y manos que se acercaban para atraerlo hacia él como un mar de lenguas serpentinas que surgían de su cuerpo. La diosa Minerva al ver el terror en los ojos del protagonista, lo tranquiliza de este modo:

N'ayez nulle peur, me répliqua-t-elle, ce n'est qu'un monstre métaphisique, qui ne peut vous faire de mal.

Cette Fille putative de Newton, cette prétendue Déesse de mon Temple, est la Sala-Gno-Silph-ondine Chimboraço, fille du génie Pithagore, et de l'imagination qui n'a plus de pouvoir ${ }^{29}$.

\footnotetext{
${ }^{24}$ Morvan de Bellegarde, Jean-Baptiste (1702): Lettres curieuses de littérature et de morale, Paris, J. et M. Guignard, p. 205.

${ }^{25}$ Christout, Marie-Françoise (2004): «La thématique des éléments, source d'inspiration du ballet en France du XVII ${ }^{\mathrm{e}}$ au XVIII ${ }^{\mathrm{e}}$ siècles», Les éléments et les métamorphoses..., op. cit, pp. 245-253.

${ }^{26}$ PARfaict, Claude et François (1767): Dictionnaire des théâtres de Paris, t. III, Paris, Rozet, p. 20.

27 Ibid., p. 19.

${ }_{28}$ Zoroastre: opéra représenté pour la première fois par l'Académie royale de musique le 5 décembre 1749 et remis au théâtre le mardi 20 janvier 1756 (1756): Paris, Vve. Delormel et fils.

${ }^{29}$ LA Rougère (1746): Le Génie ombre et la Sala-Gno-Silph-ondine Chimboraço, Conte phisique, [s.1.], A. Chimerie, pp. 8-9.
} 
Minerva le concede entonces al protagonista la posibilidad de ver al monstruo, que se trata en realidad de la maga Chimboraço, para que a través de los ojos de un Chimboracien ésta no le parezca tan terrible, descubriéndola bella, noble y sencilla. Pero también se fija en otro ser, una mujer alada a los pies de la maga, cuyo aire triste y encantador le subyugan mucho más que Chimboraço:

Je demandai à ma Conductrice, quelle étoit cette jolie Femme qui sembloit répandre la lumière autour d'elle. C'est, me répondit la Déesse, la Salamandre Subtile, qui circule dans l'Univers.

Vous êtes étonné, par exemple, de voir qu'une pierre que vous jettez vers le ciel, revienne sur vous ; C'est selon eux, parce que Subtile, Magnesie, Estherée et Celeste, dansant les vents dans les airs, l'entraînent dans leur differens tourbillons, et la chassent enfin vers vous, par le milieux de leur ronde ${ }^{30}$.

La historia prosigue hasta su final escrita en clave metafísica, donde Descartes y algunos científicos de la época aparecen en los rituales y loas como semidioses de ese Universo invisible para los vulgares ojos humanos de los no iniciados. No será hasta el final cuando se desvelen parte de las claves para poder descifrar el simbolismo contenido en los personajes.

De esta manera se demuestra cómo estos seres lograrán campar a sus anchas en los géneros literarios a partir de estos momentos, fundamentalmente en la novela y el teatro. En este sentido, ¿cuál es su papel en la sociedad de los siglos XVII y XVIII? Si se tienen en cuenta los acontecimientos de la época se aprecia, sin embargo, la posibilidad de arraigo de casi cualquier doctrina hermética o esotérica: un final de siglo XVII marcado por discusiones y luchas de carácter religioso, conlleva la entrada en un XVIII con un comienzo tan crudo como su final, ya sea por cuestiones políticas o religiosas, en el que tan sólo se destacan los esfuerzos filosóficos de la razón, la ciencia y el bien de la humanidad. Asimismo, en el polo opuesto, el pueblo pudo asistir a curaciones milagrosas, a escenas de magia y hechicería, exorcismos, y se desenvolvió entre vampiros, espiritistas, alquimistas y masones.

Aunque se abandonaron antiguos esquemas, una parte de la sociedad, la de extracción más elevada, se «moderniza» y asocia con las líneas de pensamiento de lo maravilloso $^{31}$, originando una sociedad impresionada, como dice D'Hauterive, «pour tout ce qui semblait échapper aux lois de la nature, sans prétendre donner une explication de faits, grossis souvent par l' imagination des contemporains» ${ }^{32}$. Con ese panorama los silfos y salamandras entraban en escena como unos verdaderos seres angelicales...

Sin embargo, la permanencia de los elementales en la literatura de esta época representa más un divertimento que una doctrina hermética en sí misma. La razón es que, formalmente, las obras presentadas no versan de manera expresa acerca de la existencia y comunicación con estos seres, sino que se trata de historias donde se inserta este tipo de personajes y caben estas relaciones. Lo más importante es que los relatos irán apoyados en la mayoría de las ocasiones por un apólogo moral, aunque sea implícito.

\footnotetext{
${ }^{30}$ Ibid., pp. 18-19.

31 Baratay, Éric (1996): L'église et l'animal (France XVII ${ }^{e}-X X^{e}$ siècles), Paris, Éditions du Cerf, p. 115.

32 D'Hauterive, Ernest (1973): Le merveilleux au XVIII ${ }^{e}$ siècle, Genève, Slatkine, p. vi.
} 
De ahí que donde más se viera la fuerza de los elementales fuera en un tipo de obras en las que las relaciones entre estos seres y los humanos resultaban completamente parodiadas. En ellas las características básicas de los personajes y sus relaciones se acogen a lo expuesto como fundamental en Le comte de Gabalis. Para aquél que entra en contacto con estas criaturas, la relación se enmarca dentro de la tipología de una iniciación mística en las maravillas ocultas de la naturaleza: «Considérez mûrement si vous avez le courage et la force de renoncer à toutes les choses qui peuvent vous être un obstacle à parvenir à l'élévation pour laquelle vous êtes né» ${ }^{33}$. Esta renuncia tiene un amplio componente de orden sexual. La razón no es otra que la vasta pureza de estos seres que, según explicaba Gabalis, no conocen la desdicha del pecado de Adán, dando testimonio de ello los cuatro elementos, pues éstos han sido creados para hacer de intermediarios en la distancia que separa al hombre de las cosas celestes.

Por otra parte, los que buscan manifestarse ante el género humano, lo hacen generalmente con un propósito: el de la inmortalidad que ganan con su unión mediante un quid pro quo, convertido a veces en un catálogo de virtudes y cualidades al mejor postor. Aunque para salvar las apariencias, los hombres quedan siempre como los elegidos iniciados y los elementales como los seres superiores que se dignan visitar a los humanos en sus misterios transcendentales.

En este juego de una moralidad que mira de soslayo una nota de transgresión, de una visión un tanto ácida del mundo de lo científico recientemente estrenado como tal, de la picaresca entre la realidad sensible e invisible, se insertan la mayor parte de historias presentadas en este trabajo. Se trata de obras paralelas a esa otra tradición filosófica que defiende a ultranza la existencia de estos seres, de donde parten como fuente pero para imponer su propia visión, de modo que el objeto de estudio es, por tanto, comprobar de qué manera estos autores los incluyen en sus obras y cómo es la relación entre elementales y humanos.

En este sentido, los textos estudiados presentan una serie de rasgos comunes, de entre los cuales destacan dos por su importancia. En primer lugar, el ser elemental aparece como un factor maravilloso dentro de la obra, deseado y esperado a la vez, y en segundo lugar, el papel principal por parte de los protagonistas humanos lo ostenta mayoritariamente una mujer, a la que se intenta seducir, aunque no siempre con la excusa de la inmortalidad. El caso más flagrante es Le sylphe de Crébillon hijo. Como cuento libertino inspiraría toda una literatura en la que los valores de la moralidad, reflejados especialmente en las lecturas femeninas del momento, se codean con estos textos donde un elemento perturbador acaba imponiendo su antagonismo ante una virtud más bien fingida:

Comment une essence aussi celeste que la vôtre peut-elle descendre au commerce des hommes ? - notre felicité, dit-il, nous ennuye quand nous ne la partageons avec personne, et tout notre soin est de chercher quelque objet aimable qui mérite de nous attacher ${ }^{34}$.

La presencia del elemental no deja de ser intrusista en la realidad humana por más que muchas veces el humano desee su contacto. Por este motivo, la aparición de los genios se introduce con un halo de misterio. En la novela, un modo oportuno de justificar

\footnotetext{
33 VILlaRs, Nicolas, op. cit., p. 16.

${ }^{34}$ CRÉBillon, Claude-Prosper Jolyot De (1730): Le sylphe, Paris, L.-D. Delatour, p. 39.
} 
una de estas presencias en las obras es la noche durante la fase del sueño o, mejor aún, la vigilia nocturna, cuando todo parece surgir de una ilusión muy real. El motivo de la ensoñación ofrece argumentos al pensamiento más racionalista sobre la realidad de los hechos quedándole siempre al receptor la opción de la alucinación. Pero esta estratagema de los autores no hace sino reiterar hábilmente las posibilidades de su veracidad, puesto que la duda ofrece una alternativa tan real como la propia negación de los hechos. La condesa protagonista de la obra de Crébillon argumenta así ante su amiga:

C'est un songe, je ne vous donnerai mon avanture que sur ce pied-là, il faut ménager votre incrédulité. Cependant, si c'étoit un songe, je me souviendrois de m'être endormie avant que de l'avoir commencé, j'aurois senti mon reveil ${ }^{35}$.

Así, la astucia de la protagonista con el motivo de la ensoñación le sirve no sólo para esquivar la duda sobre lo relatado en caso de connivencia con su interlocutora, sino también para excusar en caso contrario, la recepción de unos hechos alejados del decoro exigido a su persona.

Otras veces el ser elemental irrumpe con su presencia en la vida del humano de una manera adecuada a su prestigio: estatuas de increíble belleza que desencadenan al instante graves complejos de Pigmalión, palacios invisibles que aparecen de repente ante la vista de amantes desesperados ${ }^{36} \ldots$ En las obras teatrales la irrupción será más acusada por el espectador desde el punto de vista de la escenografía que de la trama, de ahí que el procedimiento esté focalizado en el personaje del elemental cuya sola presencia provoca ya asombro y carga la escena de tintes maravillosos. Uranie, una de las protagonistas de Le sylphe suppose $e^{37}$ recibe con alegría la noticia de la llegada de una sílfide que entra en la escena como uno más de los personajes sin rodearse de artificios, al igual que la apasionada marquesa de Volange esperando a su amante silfo en un rincón apartado de su jardín, quien llega como cualquier pretendiente oculto ${ }^{38}$.

De una u otra manera los elementales aprovechan los estados de soledad de los protagonistas humanos para mostrar unas veces sus voces, otras su presencia completa, pero no a todos por igual. Entre los afortunados que cuentan con su aprobación se sitúan de manera especial los personajes femeninos, las grandes seducidas del panorama literario de los elementales. Sin embargo, no todas las mujeres obtienen el visto bueno de estas criaturas aparentemente superiores, imponiéndose una clara versión en los personajes, sea del género que sean, como los de tendencia quijotesca. Quijotesca porque en su mayoría tienen el cerebro embebido de doctrinas cabalísticas, herméticas, o simplemente novelescas, creyendo en la magia y los seres elementales como una religión ad hoc que profesan con fervor esperando su redención eterna. La razón de la indiferencia de la joven marquesa de Le mari sylphe se encuentra en esas lecturas:

35 Ibid., p. 11.

36 WiEland, Christoph Martin (1802): Les Abdérites suivis de La Salamandre et la Statue, t. III, Griffet de Labaume, A. G. (trad.), Paris, Dentu.

${ }^{37}$ FagAn, Barthélemy-Christophe (1760): Le sylphe supposé, in Théâtre de M. Fagan, t. IV, Paris, N.-B. Duchesne.

38 Françols de NeufChâteau, Nicolas (1908): Le mari sylphe, in Bulletin de la Société de l' histoire du théâtre, 1908: 5-7, Paris, Société de l'histoire du théâtre, p. 792. 
Elle lit, avec avidité,

Des contes, des romans les séduisants mensonges,

Rêve aux esprits, se peint leur volupté,

Et préfère à la vérité

Le charme aimable de ses songes ${ }^{39}$.

La culta Uranie con su afición por el «saber» es la causa de la insatisfacción de Cléante, que no cree que haya remedio para ella:

Tantôt elle prend un livre, tantôt elle prend l'autre, qui tous ne parlent que de magie. Elle n'a de correspondance qu'avec les habitans de l'air ; elle ne contemple que les planettes, et elle cherchoit tout-à-l'heure les moyens de se transporter dans une isle volante qu'elle prétend avoir découverte ${ }^{40}$.

En este caso el pensamiento que rodea esta actitud femenina de cambio y de situación en un nivel de autonomía similar al masculino, se traduce en un cierto menosprecio por parte del resto de personajes, quedando enfrentados incluso los dos géneros en algunas ocasiones. Otras veces, la protagonista es una acérrima incrédula de todo lo que rodea este mundo de ideas herméticas y se sorprende al descubrir a estos seres como verdaderos, creándose un efecto contrario de verosimilitud, como el testimonio personal de una conversión.

Así pues, el resultado de esta ingesta de documentos, de la avidez de conocimiento, y sobre todo, de autoconocimiento, desemboca en un motivo recurrente a lo largo de toda la literatura sobre elementales y es el odio hacia el otro sexo. Domina especialmente ese sentimiento de aborrecimiento hacia todo lo que haga referencia a la posibilidad de mantener una relación con seres humanos sin aspiraciones transcendentes. En suma, todo lo que esté compuesto de tosca materia y no sea invisible, alejan a estas mujeres cuyos votos sagrados no les permiten contaminarse con lo terrenal. Pero este sentimiento invade a cualquiera que esté poseído por el espíritu de los elementales, ni siquiera el género masculino se libra del escrúpulo. Clodion, el personaje enamorado de la salamandra petrificada en estatua, en la obra del alemán Wieland, declara así ante otro compañero de fatigas la penuria que le ha llevado ante tal complejo de Pigmalión:

J'y contractai, vers l'époque de mon adolescente, une antipathie singulière contre les femmes et les jeunes filles que j'avais occasion de voir [...] Quelques manuscrits rares [...] me firent connaître les Génies des élémens. [...] Dès l'âge de quatorze ans, la résolution d'abjurer toute commerce avec les filles des hommes, et d'observer ponctuellement le suprême bonheur d'avoir un jour pour amante une Salamandre ou une Sylphide ${ }^{41}$.

Desafortunadamente, la mayoría de estos personajes esperan ansiosamente el amor de un ser elemental tras haber alienado su perspectiva de la realidad con estas criaturas, esperando la felicidad eterna. El Chevalier du Volcan cambia su patronímico, «de l'Oli-

\footnotetext{
39 Ibid., p. 197.

40 Fagan, Barthélemy-Christophe, op. cit., p. 7.

41 WiEland, Christoph Martin, op. cit., pp. 219-220.
} 
ve», y el nombre de pila de su criado, tras infatigables horas de estudio sobre las ciencias herméticas y alquímicas, y haber contactado con una salamandra de la que está enamorado, todo ello con la esperanza de enriquecerse al igual que otros tantos personajes de esta índole. Cyclopin se queja así de su señor:

Il dépense le peu d'or réel qu'il a dans l'espérance chimérique de trouver d'en faire. Mon occupation la plus sérieuse est de remplir des creusets, d'allumer force de charbon [...] Apprenés, Madame, que le Chevalier est frappé du trait de folie le plus singulier, et cela vient de ce qu'il est toujours dans le feu et dans les flames. Vous le dirai-je, Madame ? Il s'est mis dans la tête qu'un certain animal qu'il appelle une Salamandre, est devenue amoureuse de lui. Est-il rien de plus risible ? ${ }^{42}$

Como ocurre en este tipo de obras, Cyclopin pone el contrapunto al carácter del caballero, absorto en sus doctrinas cabalísticas e ironizado por su simple actitud de personaje despistado, ajeno a la realidad. El criado, mucho más práctico y realista, añade esa nota cómica a la obra teatral y el humor surge de esa mezcla de aparentes contrarios que son, por un lado, el sentido práctico y la supervivencia, y por otro, la falta de coordenadas reales y las falsas creencias. Son en general los allegados de estas personas, los que intentan hacer volver la razón a la cabeza de los «poseídos» por el espíritu de los elementales. Mientras ellos son considerados por los iniciados como vulgares materialistas que sólo pueden ver y creer aquello que perciben por sus sentidos, en éstos, sin embargo, se cargan las tintas con los mecanismos de la sugestión, las visiones y los sueños, para adentrarse cada vez más en este mundo paralelo.

Por otra parte, en algunas ocasiones ese rechazo frontal del otro género no ha sido el resultado de esas lecturas, sino la causa de un elemento exógeno que ha actuado en la infancia produciendo un efecto Pigmalión. Uno de los casos más terribles es el de la nodriza que imbuye ideas proféticas sobre la suerte especial de su protegida, nacida para un destino superior al del común de los mortales. Así, Julie, la protagonista de L’Amant salamandre, está segura de encontrar un día a su enamorado salamandra por unas palabras visionarias de su institutriz:

Elle ne cessoit de donner des louanges à ma beauté ; et voyant que j'étois bien persuadée de ce que je valois, elle m'applaudissoit, et me faisoit entendre qu'il n'y avoit rien dans le monde qui fût digne de moi. [...] Ne vous afligez pas encore, continua ma gouvernante ; contentez-vous de savoir pour le présent que c'est un esprit tout de flamme, autrement dit un Salamandre ${ }^{43}$.

En este tipo de obras, las imágenes de los objetos deseados se presentan bajo diferentes formas, comenzando por el aspecto soñado, querido, fruto de la imaginación y la espera, como en el caso de la joven Julie:

J'étois d'ailleurs flattée par l'idée de voir quelque jour paroître mon Salamandre sous une figure charmante. J'avois oui-dire que ces divinités habitoient dans le feu ; [...] et quand je me

42 Caylus, Anne-Claude-Philippe de Pestels de Lévis de Tubières-Grimoard (conde de) (1748): La Salamandre ou l' empire du feu, in Les Amusemens des fées, $1^{\text {ère }}$ partie, Neufchâtel, [s. n.], pp. 72, 74.

${ }^{43}$ CoIntreau [(1756) 1788]: L'Amant salamandre ou les aventures de l'Infortunée Julie, Amsterdam-Paris, [s.n.], coll. «Voyages imaginaires, songes et romans cabalistiques» n. ${ }^{\circ} 34$, p. 334. 
trouvois seule, je comptois voir un tourbillon de feu s'élever du milieu de la cheminée, dont devoit, suivant mon idée, sortir mon amant, pour s'élancer dans mes bras ${ }^{44}$.

Ante esta perspectiva de cerebros congestionados por las más peregrinas ideas sobre los elementales, de rechazo y escrúpulo de la realidad mundana y de las relaciones entre géneros, los genios se deslizan en estas obras como factores de intrusismo. Irrumpen en una realidad ya organizada que no les pertenece y que arrebatan con vistas a un futuro o a un presente lleno de grandes esperanzas, pompa y boato pero, en la mayoría de los casos, con escaso o ningún convencimiento.

Tarde o temprano los elementales se presentan a la vista de sus elegidos. En el caso de Clodion esto sucede bastante pronto, más bien la visión de esta mujer salamandra es la que produce desde un principio tal impacto en el personaje, que se impone como el desencadenante del resto de la historia:

Une jeune dame qui sommeillait sur ce lit, captiva mes regards dès l'entrée. Elle était couverte jusqu'aux pieds d'une tunique couleur de feu, drapée à la manière des Grecs. [...] Le feu de ses yeux étincelait à travers le double voile qui, de son front, descendait jusque son sein ${ }^{45}$.

La (des)afortunada Julie encuentra a su amado Salamandra la noche de su cumpleaños, cuando la reencontrada nodriza le propone realizar un pequeño espectáculo de fuegos artificiales. Julie divisa una enorme bola de fuego a lo lejos que se sostenía inmóvil en el fondo del jardín. Aterrorizada, sólo tiene fuerzas para conocer de qué se trata de parte de su cuidadora, que parece conocer de primera mano cuál es el fenómeno que allí está ocurriendo:

Nous apperçûmes contre le mur un homme de riche taille [...]. Eh bien, mademoiselle, comment trouvez-vous ce beau cavalier qui s'offre à vos yeux ? il est d'autant plus digne de vous, qu'il est tout divin, et de plus revêtu d'une belle humanité ; ne mérite-il pas le sacrifice de toute cette foule de mortels que vos charmes rendent vos esclaves ? [...] Par son pouvoir, le tems ni l'usage n'altéreront jamais vos charmes ; vous aurez toujours les graces de la jeunesse ${ }^{46}$.

La salamandra del Chevalier du Volcan, sin embargo, no puede hacerse visible si no es bajo los rasgos de un ser humano, para lo que escoge a la condesa que la une en amistad al caballero, primero su voz y, más tarde, su físico al completo. En todos los casos se les exige, al igual que en Le comte de Gabalis, la fidelidad más pura y la renuncia a toda relación con otros seres humanos, incluso el abandono de la familia.

Llegados a este punto es necesario recordar que el fin de todos estos textos es, sin duda, moral. En ellos transluce un apólogo tan invisible como los propios silfos, pero tan contundente como sus promesas de inmortalidad. Ésta era ni más ni menos la finalidad perseguida por el propio Montfaucon de Villars, porque si con su obra participaba en la influencia del motivo de los seres elementales en la literatura posterior, su contribución

\footnotetext{
44 Ibid., p. 342.

45 Wieland, Christoph Martin, op. cit., pp. 224, 240.

${ }^{46}$ Cointreau, op. cit., p. 370.
} 
moral no es menor. Cada una de las obras propuestas tiene su moraleja final, alguna la lleva incluso insertada en el título.

Pero ¿qué tipo de apólogo?, ¿contra qué o quién? En primer lugar, sin duda, contra las propias teorías ocultistas y en última instancia, y relacionado con esta idea, contra esa falsa sabiduría que hace perder la cabeza y desvía de los verdaderos propósitos o del sitio que cada cual debe ocupar. La razón principal es que una idea equivocada, un traspié sobre la propia identidad, lleva a estas mujeres a buscar más allá de los límites de lo razonable lo que nunca encontrarán dejando pasar las verdaderas oportunidades. Porque todos los personajes están medidos conforme a la virtud y a lograr un matrimonio ventajoso y para conseguirlo hay que utilizar incluso el engaño.

Ésta es la verdad oculta tras los silfos, las salamandras y las ondinas: salvo raras excepciones, la piel con que se visten para presentarse ante los humanos no es más que la presencia prestada de otro personaje, o un mero disfraz adecuadamente confeccionado para la ocasión. La mejor manera de destruir la idea de los elementales es apropiarse de su imagen para, mediante un mecanismo de la ilusión, mostrar el engaño que se ha perpetuado a lo largo del texto.

El amante salamandra de Julie que aparecía todas las noches, aparentemente en la invisibilidad más absoluta para el resto de ojos mortales, comienza a ser visto en adelante por los criados de la casa. De esta manera finalmente, tras ser víctima de un intento de asesinato, se descubre a sí mismo en su lecho de muerte como el hijo ilegítimo de su institutriz, quien para encontrar una vida más ventajosa quiso rodearse de llamas de pasión, pero siendo tan mortal y humano como ella. La desgraciada historia de esta joven, refleja el lado brillante del aparente relato mágico de características maravillosas, para dejar salir a la luz más tarde la perspectiva moral oculta, que no era otra que la necesidad de velar por los hijos y de conocer las personas de las que se rodean ${ }^{47}$.

La encendida salamandra de Clodion y la evanescente estatua de Osmandyas no son más que los respectivos hermanos de cada uno en un virtuoso intento de unir las dos familias y acabar con esas ideas herméticas, donde todo queda sentenciado al final: «Clodion crut aimer une Salamandre dans la personne de Thermutis» ${ }^{48}$. Sin embargo, la historia llega a buen puerto y regala un final feliz pese a descubrirse la verdad de ambos personajes fabulosos.

Pocos de estos personajes se salvan de no ser más que un triste trasunto humano de estos genios maravillosos y, así, la lección moral continúa. Las obras teatrales son aún más claras y ese mecanismo de ilusión propicia la temática del doble para ironizar sobre estos seres, donde amantes y maridos se transforman y desdoblan en las figuras deseadas por sus compañeras, sin que éstas lo sepan. Similar es, por tanto, el fin de la historia de amor del Chevalier du Volcan, donde la pretendida salamandra no es, ni más ni menos, que la misma condesa que aparentaba ceder su voz y su cuerpo a la invisible criatura, aunque esto sea revelado desde el principio de la pieza y guardado en complicidad entre la dama y el criado.

Por otra parte, la temática del disfraz o el «engaño» perpetrado con el nombre y la piel de salamandras y silfos conlleva también el despliegue de los mecanismos que hacen

\footnotetext{
47 BILA, Constantin, op. cit., p. 107.

48 WiEland, Christoph Martin, op. cit., p. 282.
} 
funcionar los valores asociados a la predeterminación de las formas. El cambio físico de los personajes, metamorfoseados en seres fabulosos, tan sólo esperados por una parte restringida de los mismos, desata igualmente un cambio psicológico y de valores en la relación entre ambos, puesto que por una parte aquéllos que son incapaces de recibir del otro, se descubren en ese nivel bajo la máscara que predetermina las expectativas asociadas a su atuendo.

En efecto, los personajes se mueven dentro de este tipo de obras y escenas dentro del mundo de los posibles. Las relaciones que se establecen entre ellos se consolidan no en la realidad a la que están sometidos, sino en sus límites, en la frontera de ese otro plano virtual en el que uno puede convertirse en el Otro y la identidad se desplaza. Sólo de esa manera algunos personajes son capaces de recibir y de dar, fuera de los formalismos y del protocolo que se les supone por su condición, no sólo social sino incluso personal. He aquí entonces el sentido positivo de los seres elementales en estas obras de las que a veces sólo se ha destacado la caricatura de unas corrientes herméticas y pseudofilosóficas, o bien la inadecuación a la realidad de unos personajes que representaban a perturbados, ajenos a las exigencias de la vida. La máscara de los elementales permite que todo aquello que está del lado de los factores vitales se una al plano en que éstos sólo forman parte de algo imaginado, de la realidad de la ensoñación y la expectativa, de manera que se buscan otros mundos posibles para evitar que el intercambio y la comunicación humanos acaben por agostarse en esta realidad.

Se podría decir entonces, en conclusión, que la moda de los seres elementales en la sociedad francesa de los siglos XVII y XVIII, es el resultado que toma como pretexto las corrientes herméticas que tradicionalmente comienzan a tener peso social a fines de la Edad Media y que siguen vinculadas de forma paralela durante este siglo, para tratar una temática que producía mayor preocupación. Si una de las diversiones de la alta sociedad consistía en ocuparse de estos fenómenos extraños de los que habían oído hablar, el éxito estaba asegurado si un segundo nivel de lectura aparecía detrás. De este modo, bajo la falsa apariencia del hermetismo más absoluto y de las experiencias vividas al respecto, el protagonismo de la razón desterrando a lo oculto se deja patente en estas obras. El primer nivel de lectura queda así subordinado a la verdadera interpretación, que no es sino la desmitificación de todo atisbo maravilloso paralelo al conocimiento y la ilustración, a lo que hay de moral en ellos, sin encorsetamientos pero con lucidez. 